\title{
ANTROPOLOGÍA Y CREENCIA. CARMELO LISÓN TOLOSANA JAPONIZANDO
}

\author{
Anthropology and Belief. Carmelo Lisón Tolosana \\ Japonizing
}

Antropologia e crença. Carmelo Lisón Tolosana Japonizando

\author{
José Antonio GonZÁlez AlCANTUd \\ Universidad de Granada \\ jgonzal@ugr.es
}

Fecha de recepción: 12/01/2021

Fecha de aceptación:12/02/2021

RESUMEN: Uno de los libros más singulares de la obra de Lisón Tolosana es La fascinación de la diferencia. La adaptación de los jesuitas al Japón de los samuráis, 1549-1592, aparecido en 2005, en plena madurez del autor. Singular porque se consagra a analizar un país y un período histórico ajeno a las posibilidades del trabajo de campo, pero empleando los recursos interpretativos de la antropología, sobre todo lo que se refiere a las extrañezas culturales. Lisón hace esta aproximación con gran empatía hacia la labor misional de los jesuitas en un Japón convulso en el que el catolicismo es aceptado con convicción como rechazado radicalmente.

Palabras clave: Japón; samuráis; jesuitas; Valignano; embajada japonesa.

ABSTRACT: One of the most singular books in Lisón Tolosana's work is $L a$ fascinación de la diferencia. La adaptación de los jesuitas al Japón de los samuráis, 1549-1592, published in 2005 in Spanish, in maturity of the author. Singular because it consecrates in analyzing a country and a historical period, outside the possibilities of field work, but using the interpretive resources of anthropology, especially what refers to cultural differences. Lisón makes this approach with great empathy towards 
the missionary work of the Jesuits in a troubled Japan in which Catholicism is accepted with both conviction and rejection.

Key words: Japan; samurai; Jesuits; Valignano; Japanese embassy.

RESUMO: Um dos livros mais singulares da obra de Lisón Tolosana é La fascinación de la diferencia. La adaptación de los jesuitas al Japón de los samuráis, 1549-159, publicado em 2005, em plena maturidade do autor. Singular porque se consagra a analisar um país e um período histórico cheio as possibilidades do trabalho de campo. Porém, empregando recursos interpretativos da antropologia, sobre tudo o que se refere as diferenças culturais. Lisón faz esta aproximação com grande empatia ao trabalho missioneiro dos jesuítas em um Japão convulso em que o catolicismo é tanto aceito com conviç̧ão quanto rejeitado radicalmente.

Palavras-chave: Japão; samurai; Jesuítas; Valignano; Embaixada do Japão.

En el crepúsculo de sus días hice una visita al maestro Carmelo Lisón Tolosana, corría el año 2016, y acaba de salir al público la película de Martin Scorsese Silence. Carmelo me preguntó con gran curiosidad y expectación si yo la había visto, a lo que contesté negativamente, aunque compartía el mismo interés que él. Me dijo que la había encargado, y que tenía un gran interés por ver cómo Scorsese había reflejado la problemática jesuítica en Japón, que él mismo había recogido en parte, en el período 1545-1592, en su volumen La fascinación de la diferencia, publicado unos años antes (Lisón, 2005). No me abandonaba a mí tampoco la curiosidad tras haber visitado por aquella época las misiones jesuíticas del norte de Argentina. Tema siempre traído a colación, por mi parte, con una mezcla de admiración y rechazo. Leopoldo Lugones sostenía con el pensamiento en el «imperio jesuítico" americano que en él se había impuesto la razón a la estética: "Mientras las demás órdenes abundan en poetas, en ésta hay, sobre todo, hombres de ciencia. El arte le interesa poco» (Lugones, 1985: 78-79). Y esto a mí en particular me hacía y me hace aún poca gracia. Sin embargo, en Carmelo Lisón Tolosana la vida de la Compañía de Jesús ejercía una gran fascinación por cómo se había acercado a las diferencias culturales irreductibles, con sagacidad y raciocinio.

El director Martin Scorsese es conocido por haber abordado el mundo jesuítico desde la creencia, pero teniendo presente la disociación entre ser creyente y ser católico, concebidos como cosas distintas. En su diálogo con el jesuita Antonio Spadaro a propósito de Silence así se lo hace ver. Manifiesta Scorsese al padre que no le interesa la Iglesia en cuanto institución, sino más bien los principios relacionados con la fe, la resurrección, la encarnación, la compasión, el amor... (Spadaro, 2017: 24). En el terreno concreto de su película, Scorsese le cuenta al jesuita que había descubierto la problemática cuando en 1988 estaba interpretando un papel en la película Sueños de Akira Kurosawa, y cayó en sus manos la novela de Shûsaku Endô Silence. La narración ficcional de Endô tiene un gran valor 
aproximativo, como la película, aunque existan algunas dificultades cronológicas para ubicar a Valignano, dado que este murió en 1606, mientras que la apostasía de Ferreira se sitúa en 1614 (Endô, 1988). Pero, en fin, toda la libertad para el arte, que debe conducirnos a la esencia de las cosas.

La obra de Endô es poderosa, puesto que, como en cierto momento se nos dice, el leitmotiv es el silencio de Dios, frente al sufrimiento infligido a los cristianos japoneses: "Ya han pasado treinta años desde que comenzó la persecución y, aunque esta tierra negra del Japón estalla de gemidos cristianos (...), Dios tiene delante a las víctimas de este horrible sacrificio inmoladas a él, y aún continúa en silencio» (Endô, 1988: 56). El asunto clave, pues, es el silencio de Dios frente al sufrimiento de quienes dan testimonio de su fe hasta llegar al martirio. En el filme de Scorsese a pesar del carácter apologético del valor de los jesuitas en Japón, e incluso de haber sido dedicado explícitamente a los cristianos japoneses, existe la intención de darle la mayor verosimilitud, sin caer en el panfleto hagiográfico. La película no está reforzada emocionalmente con una banda sonora, y los personajes de los bonzos y sobre todo del gran inquisidor budista y del traductor de aquellos son tratadas en su propia lógica: "Hemos estudiado profundamente vuestra religión", le espetan al sacerdote. De hecho, esto era así, como se verá sobre todo en el tratado de refutación del cristianismo, escrito por Sessô Sôsai Taiji Jash $\hat{u}-$ ron, que, a mitad del siglo XVII, en 1648, defendía el budismo y negaba que fuese una variante del nihilismo, como sostenían los cristianos (Pinto, 2002: 98 ss). Así, la doctrina budista, sería también una senda de misericordia, que contempla al cristianismo como una avanzadilla de conquista espiritual, negándose a ceder. Pone barreras definitivas y brutales el budismo al catolicismo, tras un siglo de contacto más o menos amistoso entre ambas creencias. De las "conquistas espirituales» ya han dado cuenta dado cuenta en la prueba americana desde Robert Ricard hasta Serge Gruzinski, precisamente a través de los procesos de aculturación, sincretismo o hibridación (Ricard,1986; Gruzinski, 2013), pero siempre con un carácter impositivo en términos de absolutos. Quizás sólo el arte, de la incorporación de la iconografía local al imaginario cristiano se produzca una verdadera hibridación en el sentido dialógico (Gruzinski \& Mermet, 1994).

La segunda experiencia con el tema tiene que ver con la visita a Coria del Río, localidad aledaña a Sevilla, donde el Guadalquivir vuelve a tener una apariencia salvaje, ya que para cruzar de un lado a otro de su curso hay que hacerlo en barcaza, al no haber puentes, y se come en su parque un pescado único del río, el albur. Existe allí una escultura frente al río erigida al samurái Hasekura Tsunenaga, quien en nombre del daimio de Sendai llegó a Andalucía camino de Roma en 1614. No fue la primera embajada japonesa, auspiciada por los jesuitas, pero posee la peculiaridad de que el padre Luis Sotelo era sevillano, y por eso cabe suponer remontó el río andaluz. El recibimiento sevillano fue excelente:

El vent'uno d 'Ottobre dell'anno medesmo la Città (Sevilla) fece un'altra dimostratione di maggior cortesía, per ricevimento dell'Ambasciatore, e del Padre Sotelo, 
mandando carrozze, cavalcature, e gran numero di Cavalieri, \& altra nobiltà, che servissero con ordinedi cavalcata, \& in forma grave. Onde uscendo l'Ambasciatore di Coria, viddero con molta ricreatione l'honore preparato, la pompa de'Cavalieri, e cavalli, \& il numero grande della gente, che l'accompagnò sei miglia lontano da Siviglia (Masamune, 1615: 31).

Como se observa, por las fuentes de la época, la llegada a Sevilla, a un tiro de piedra de Coria, fue de una gran solemnidad, habida cuenta que el padre Sotelo era natural del lugar.

Y la tercera impresión que me invitó a dialogar con la obra japonista de Carmelo Lisón fue una estancia en Roma, donde él había acudido en numerosas ocasiones mientras investigaba sobre todo a Valignano. Me interesé por el asunto de los japoneses en Roma, por puro diletantismo, y exploré algunos de sus rastros. En ese camino quedé sorprendido al comprobar que en el palacio del Quirinal, antigua residencia estival de los papas, cerca del noviciado jesuita de san Andrés del Quirinal, se encontraba representada en el friso del techo de una de sus enormes salas una de las antiguas embajadas japonesas.

Habida cuenta de las motivaciones, he de destacar, en primer lugar, la gran atracción que ejerció el Extremo Oriente en el profesor Lisón, asunto sobre el cual la crítica en España ha pasado muy de largo, probablemente por la extensión de su obra basada en trabajo de campo intenso en Galicia. El artículo inicial sobre el Extremo Oriente de Lisón Tolosana se remonta a finales de los años setenta, y trata de un misionero aragonés, el Padre Adriano de las Cortes, sacerdote jesuita, que en 1625 se aventura durante un año en la región cantonesa, sufriendo prisión. Lisón, aragonés como el padre De las Cortes, trabajaría con el manuscrito aún sin publicar de la British Library, y tomaría cuidadosas notas de él (Lisón, 1978). Sabemos de su visita a Japón en 1987 (foto n. ${ }^{\circ}$ ). Más adelante en el prólogo que haga a la primera edición contemporánea del viaje del jesuita aragonés, que hizo su discípula la profesora Beatriz Moncó, lo firma en Cantón en marzo de 1991 (Cortes, 1991). En él comienza induciéndonos a pensar en el paisaje humano que se extiende ante sus asombrados ojos. Es consciente Lisón que no deja de ser un viajero antropológico que no puede penetrar en los arcanos de la cultura local si no es a través de un trampantojo como es la literatura histórica. Consciente de ello en ese mismo año cuando pronuncie una conferencia en la universidad Zhongshan de Guangzhou sobre los primeros misioneros españoles en China, ya apunta hacia el método del encuentro cultural o de la "conquista espiritual»:

Puesto que van a encontrar modos de comportamiento, ceremonias y creencias diferentes y aun raros y chocantes, deberán ir prevenidos para detener su celo religioso, reprimir sus reacciones primarias ideológicas, y no molestarles en sus ritos y devociones. La estructura narrativa deja bien patente cómo el Otro, sus leyes y su religión son honorables, están en pie de igualdad (Lisón,1992: 45). 


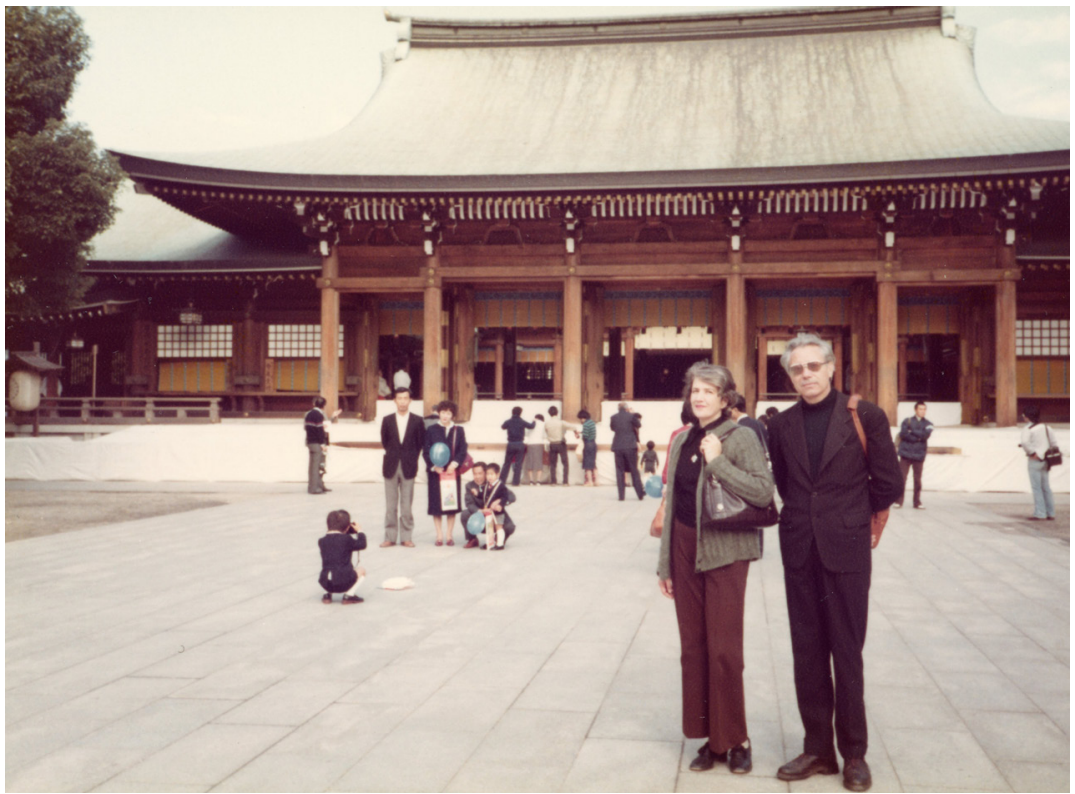

Foto n. ${ }^{\circ}$ 1: Carmelo Lisón y Julia Donald en Ringshide (Japón), octubre 1987 (Fundación Lisón-Donald. La Puebla de Alfindén).

Lisón siempre quiso mostrar la existencia de una racionalidad en hechos tales como las actuaciones de la Inquisición y en las misiones. No se trataba en estos casos concretos de promover la conquista a sangre y fuego, cosa inverosímil ante un pueblo de guerreros bien pertrechados como los samuráis. Al no ser una civilización marcada por la inferioridad ni cultural ni tecnológica, sino de un pueblo avanzado, y de convicciones muy firmes, con una religión y cosmovisión propia, había que explorar la racionalidad que había en el otro lado, en particular entre sus élites. Francisco Javier, procedente de la costa india, estudiará con curiosidad a esas elites:

Javier llevaba ya más de tres un año preparándose concienzudamente para su empresa nipona y (...) había estado recabando noticias sobre aquella gente y tierra, de comerciantes portugueses que la visitaban, desde 1543 (Lisón, 2005: 11).

La información principal la obtiene el jesuita del relato del capitán Jorge Alvares. A través de él llega a la conclusión de que los japoneses son un pueblo avanzado, con lengua, territorio y sistema de creencias potentes. Y en esas fortalezas encuentra el punto fuerte para intentar atraer a sus principales, los samuráis. "No quiere ni lanzas ni espingardas ni coerción institucional ni imposición de costumbres; su pensamiento es mucho más sofisticado; quiere ganarles pacíficamente 
por convencimiento libre y aquiescencia personal, quiere convencerles por la sola fuerza de la razón", escribe Lisón (2005: 14). En un momento determinado, presa de su optimismo pronto desmentido, Francisco Javier prevé un "deslizamiento» del zen hacia el catolicismo. "Javier se equivoca, pero es auténtico", sentencia Lisón. Un equívoco que puede hoy justificarse porque la variedad del budismo, implantado en lugares de Asia muy diferentes, parecía inclinarlo a la aculturación (Gellner, 2001: 319-324). Pluralidad doctrinal que, debería intuir Francisco Javier y los jesuitas que lo siguieron, el estado de guerra intestino en el Japón del siglo XVI los beneficiaba (Boxer, 1967: 41-90).

A pesar de la admiración que le profesa Lisón Tolosana a la obra en el Japón del siglo XVI de los jesuitas, a partir de la prédica de san Francisco Javier y hasta llegar a Alessandro Valignano, no deja de observar la distancia entre el deseo de conocer y el impulso directo de convertir. Un coetáneo, el padre Luis Fróis, había señalado la violencia que suponía a veces «el contraste entre la disposición amable de los bonzos y la bravura del ataque de Javier», quien no conocía más que rudimentos de la lengua japonesa ${ }^{1}$. Le escandalizaba en particular la sodomía que practicaban los monjes budistas, de la manera más descarada y natural. Para lograr el aprecio samurái, sin embargo, comprendió que debía vestirse con una cierta alcurnia y rodearse de un cierto protocolo, lo que le dio buenos resultados en el acercamiento sobre todo a los notables (Lisón, 2005: 33-34). «Éstas fueron las muchas luces y algunas sombras de Javier, ambivalente del triunfo de la imaginación mística sobre la praxis y de la innovación sobre la rutina, raro emblema dual de la abnegación en pro del Otro y ocasional gesto sombrío de rigidez», concluye Lisón (2005: 34).

Especial interés tiene para el profesor Lisón, el padre Torres, sucesor de Francisco Javier, que mayor conocedor del país, desarrolla nuevas tácticas. Aunque continúa predicando en la calle, como su antecesor, va reduciendo su política de conversiones al ámbito de lo íntimo, de la casa, y sobre todo se interesa, conociendo más el país, en las disputas teológicas del zen: «Se interesaron por la secta zen por sus continuas meditaciones y bellos símiles buscando satori o iluminación espiritual y también por su preferencia por una forma de disputa llamada zenmondou en la que una parte propone y formula un problema ante un auditorio y la otra responde rápidamente, terminando con uno de los contendientes vencido, discusiones" (Lisón, 2005: 53). En cierta forma eran un recordatorio, nos dice Lisón, de las disputas teológicas en las que se habían educado los jesuitas.

No obstante, no todo eran disputas educadas. Según nos relata en documentado estudio el diplomático H. Nagaoka la sagacidad de los jesuitas para

1. Este padre, Luis Fróis (1532-1597), que vivió en Japón veintidós años, fue muy prolífico en la escritura, y dejó un volumen comparativo inédito de las costumbres europeas y japonesas, depositado en la Real Academia de la Historia española, recientemente publicado, que es de gran interés antropológico (Fróis, 1585). 
introducirse en el mundo japonés, aprovechando el período de disputas citado fue grande, así como las posibilidades que les ofrecía el comercio, respaldado por los portugueses en especial, cuyo predominio apoyaba la Compañía de Jesús sin ambages (Nagaoka, 1905: 225-235).

Uno de los apartados más interesantes, y donde Lisón Tolosana, despliega como en otras obras suyas - La Santa Compaña, en particular- toda la potencia interpretativa de la hermenéutica es en el capítulo consagrado a Alessandro Valignano, el jesuita de origen napolitano. Nos traza una magistral biografía en pocas páginas, en la que Valignano tras haber estudiado en Padua y haber alcanzado el grado de doctor, decide a los veintisiete años tomar las órdenes. Valignano se expresaba preferentemente en castellano, aunque él y su linaje tomasen parte el partido antiespañol en el Nápoles ocupado. En breve tiempo se sitúa en el epicentro de la orden, exponiendo su deseo de ir a misionar. Japón lo espera, y pide, que dadas las dificultades de comunicación -las cartas tardan años en llegar-, se le confiera autonomía y capacidad suficiente para tomar decisiones. Se enfrente así a un Japón, del cual valora, como sus antecesores, su organización social, su jerarquía, y su capacidad de discernimiento racional, pero también encuentra el obstáculo del budismo, de los bonzos, que no creen en «ultimidades», ni mucho menos en otras existencias, ni en el sentido del pecado propio del cristianismo, que incluía lo que más escandalizaba a los jesuitas: la práctica generalizada de la sodomía (Lisón, 2005: 93).

En estos momentos acontece la primera embajada japonesa a Europa, a Roma, en 1584, enviada por los daimios de Otomo, Arima y Omoura, que, según fuentes japonesas del principio del siglo XX, se habían hecho bautizar y que «se hicieron destacar entre los cristianos más ardientes e incluso más fanáticos» (Nagaoka, 1905: 239).

Lisón detiene su relato en el momento en que los bonzos y samuráis viendo el avance del cristianismo y cómo este afectaba a su estructura jerárquica e independencia, contraatacan con los martirios primigenios de Nagasaki. Primero, habían sido desterrados los jesuitas, y ahora los franciscanos, procedentes de Filipinas, tomaban su relevo con escaso éxito. Los bonzos vieron a los franciscanos como un obstáculo, y tramaron en su contra (Nenclares, 862: 5-66). Durante algún tiempo, coexistieron con los jesuitas, a quienes se había dado seis meses para abandonar el país. En realidad, Japón estaba intentando encontrar en esos momentos turbulentos su propia vía religiosa, con la instauración de un pensamiento confuciano propio liberado del lastre de los monjes budistas (Whitney, 1987: 166-167).

El caso de Cristovão Ferreira, el jesuita que apostató en 1614, pasándose al lado budista, y escribió un folleto denunciando las debilidades teológicas del cristianismo, es un caso de ateología, que bien podría relacionarse con la expansión del zen como una espiritualidad sin dios e incluso ateísta (Onfray, 2005: 58). Desde este punto de vista la batalla, que libraron los jesuitas en Japón era trascendente, y sus efectos llegan hasta el día de hoy. 
Poco propenso a mostrar su propia personalidad a lo largo de su obra, el profesor Carmelo Lisón Tolosana nos ofrece en el centro del volumen unas imágenes de la pintura namban, en las que se ven reflejada la presencia de los jesuitas en el arte tradicional del Japón del siglo XVI. Con ese motivo hará una de sus pocas confesiones personales, dado que siempre ha sido propenso a no mostrarse en sus investigaciones: «No puedo por menos de agradecer las atenciones que recibí en el Museo de la ciudad de Kobe, donde me abrieron los almacenes para que pudiera admirar sus magníficos namban en el período en que no estaban expuestos». También agradece las mismas atenciones en Lisboa, Osaka y Nagasaki (Lisón, 2005: 98). Auténticas «vividuras», pues.

Lisón, que procuró eludir cualquier connotación conflictual puramente política, se inclina por el análisis cultural. Recuerdo que con motivo de un congreso promovido por él sobre la interpretación antropológica diferí con mi maestro del alcance que tenía para la política propiamente dicha la hermenéutica. Me había leído los escritos políticos de Paul Ricoeur y me parecían paupérrimos, ya que no pasaban de ser pronunciamientos humanistas sin más enjundia (González Alcantud, 2000). No pensaba de la misma manera Lisón, justo por el rol que otorgaba a la cultura. De hecho, desde el año 1983, su obra había menguado en influencia en ciertos medios antropológicos funcional-marxistas por su decidida apuesta por la hermenéutica cultural, como método interpretativo. Precisamente allí había comenzado con una anécdota vivida en un templo de Kioto, para inferir de ella que, "no nos conformamos hasta que logramos desvelar en cada comportamiento, relación y expresión humanas, su especificación y mismidad, su totalidad antropológica», lo cual nos hacía distintos del resto de las ciencias sociales (Lisón, 1983: 123). Todavía más, esgrimirá que una característica indeclinable del método antropológico es «el empeño por conquistar la lejanía cultural y la especificidad; su quehacer fuerza al antropólogo a hacerse otro, apropiándose los significados del Otro" (Lisón, 1983:126). Y en esa línea pondrá por delante la supremacía del símbolo, y su productividad en el hecho local (González Alcantud, 2012).

Leámoslo ahora, a propósito del método de Valignano: "Este modo de existencia viene construido y regido desde y por una categoría discriminatoria ontológica: la diferencia (...), categoría que identifica e incluye -nosotros- a la vez que excluye y separa -ellos-; nos coloca el visitador [Valignano] de lleno en el núcleo cultural. La cultura, cada cultura es un sistema de diferencia» (Lisón, 2005: 141). Lisón piensa, con Valignano, la cultura es un universal que, "se esfuerza también no sólo en focalizar y subrayar las divergencias sino en resaltar a la vez las convergencias de su homogabilidad, hecho importante porque añade una tercera dimensión al cuadro: la Cultura, con mayúscula, esto es, el caudal humano que proviene de la común humanidad" (Lisón, 205: 141). Lisón es consciente que el método no es nuevo, que entre otros el jesuita Valigano ya lo ha ensayado siglos antes.

Llama la atención que el profesor zaragozano al hacerse eco de la misión nipona que Alessandro Valignano despachó a Roma en 1584, sólo haga referencia a la perspectiva del jesuita, que desea que los embajadores admiren las grandezas 
de la cristiandad (Lisón, 2005:118). Excluye -desconocemos por qué- el impacto en la curia romana y en el viaje de tránsito de personajes tan exóticos. El prontuario de ceremoniales, Il Ceremoniale, que había escrito Valignano para adaptar los jesuitas a la vida japonesa, llamado originalmente Advertimentos e avisos acerca dos costumes e catangueses de Jappāo, que atrae a Lisón Tolosana, llegó con la embajada samurái, para ser presentado al general de la orden, el cardenal Claudio Acquaviva:

Quando Alessandro Valignano lasciò il Giappone nel 1582, portò con sé il manoscritto del suo «Cerimoniale», con l'intenzione di consegnarlo personalmente a Roma al Generale dellordine Claudio Acquaviva e sottoporlo alla approvazione (...) Proseguire il viaggio non fu posible al Valignano e l'importante documento arrivò a Roma affidato a Diogo de Mezquita, accompagnatore della ambasceria giapponese (Gunji, 1985: 49).

La embajada de 1584 desembarcó en Lisboa, y se volvió a embarcar en Alicante, haciendo un tránsito ibérico que pasaba por Madrid, Toledo, Villarejo, Belmonte, Murcia y Orihuela. Fue recibida en Madrid por el mismísimo Felipe II con gran pompa. Estaba constituida la comitiva por cuatro jovencísimos japoneses, frisando los catorce años de edad. La razón para enviarlos con esa edad, nos dice Gunji, es la mayor maduración que tenían los jóvenes japoneses, por la mayor libertad que se les concedía. Causaron gran expectación a su paso, e hicieron un relato de su viaje, que se da por perdido. De todas formas, se tiene constancia del efecto exótico que produjeron por donde transitaron, e incluso de la entrada en Roma. De esta última se sabe que se valorará si han de hacerlo discretamente o con toda la pompa, debido a que debían ofrecer "obediencia» al papa (Igawa, 2020). Se opta finalmente por una entrada triunfal, una vez compraba la intención de rendir obediencia, pero también con probabilidad porque la recepción en Florencia había sido extremadamente vistosa.

Lisón no hace alusión, por tanto, a la entrada de los japoneses en Roma, sino que penetra en lo que dice Il Ceremoniale. Una de las cuestiones esenciales que destaca Valignano es que los japoneses, sobre todo la gente principal, son personal muy ceremoniosas y de mucho pulimento, por lo que los jesuitas, con fama de gente bárbara y no muy higiénicos, tendrán que hacer un verdadero esfuerzo de adaptación en sus costumbres casi tan importante como el lingüístico. Hace Valignano una suerte de prontuario de recomendaciones en el comportamiento (Lisón, 2005: 152 ss). «En el primer capítulo -escribe Lisón- plantea un problema de valor, pero en conexión con la identidad y la dignidad de la persona: ¿quiénes somos?, se pregunta. La respuesta a esta formulación identitaria es audaz y arriesgada para el tiempo jesuítico: somos bonzos de la religión cristiana, definición que resonó estridente y destemplada en la casa generalicia de Roma» (Lisón, 2005: 156).

Ahora bien, la distancia entre mantener la identidad propia en medio de la inmersión total en la alteridad nipona, y en las ceremonias culturales marcadas por un sistema religioso que se combate abiertamente, crea angustia en los jesuitas. 
Este procedimiento interior que llegará con las apostasías, y en particular la del padre Ferreira convirtiéndose en bonzo, y escribiendo un opúsculo razonado de la suya de las razones que la avalan, será la culminación de esa tensión. No obstante, el marco temporal que se impone Lisón, 1549-1592, no le permite abordar el affaire Ferreira. Este, sin embargo, está en la base del libro de Endô y de la película de Scorsese. En el fondo el caso Ferreira cierra el deseo de acculturation formal de los jesuitas. El padre Cristovão Ferreira, pasado con todas sus armas al lado budista, causó una gran conmoción en la cristiandad, sólo compensada por el heroísmo mostrado por los mártires coetáneos, justificando asimismo la política anticristiana de los samuráis. Cuando apareció publicado en 1927 el opúsculo anticristiano de Ferreira la polémica se acentuó. Como llegó a ser conocido a través de una copia conservada por una familia se cuestionaba su autoría, añadiéndose que se ponía en duda la capacidad para escribir correctamente en japonés o expresarse en lenguaje confuciano del antiguo jesuita (Cieslik, 1974: 33).

Cuando la obra de Lisón Tolosana encuentra su culmen es en el momento que va llegando a su final, y el autor desprovisto ahora de toda la erudición previa, comienza a volar por sus lares teóricos, con su particular estilo literario: «El rationale valigneano formula una ecuación relativamente simple: a movimientos corporales, posiciones y espacios ocupados corresponden honra, honor, fidelidad, decoro, derechos, homenajes e intercambios reglados por y según dignidad, nobleza, posición, cualidad, atributos y mérito personal, lo que traza a su vez un organigrama de valores que en línea recta nos lleva al núcleo interno, al ethos y pathos de una cultura, lo que quiere decir que el espíritu de la cultura se hace tangible en la actuación fenoménica del cuerpo» (Lisón, 2005: 170). Frente al Ceremoniale del intrépido visitador Valignano, entregado por la embajada japonesa de 1584 al padre general de la Compañía Acquaviva, argumenta éste, consciente de los peligros que acechan, la dificultad de pasar al lado del otro con armas y bagajes.

Finaliza Carmelo Lisón Tolosana con algunas consideraciones de método que tienen validez genérica. Sobre el género biográfico: es consciente que lo ha empleado a fondo en su recorrido, privilegiándolo sobre el contextual. Se ha apoyado en el intratexto y en el paratexto, pero no en el contexto. Después de confesarnos que resulta prácticamente imposible penetrar en la mente de los otros, señala Lisón:

Para iluminar de alguna manera su significado he ido acumulando fechas, actuaciones, hechos y sucesos, contexto y narración, pero los hechos no sustituyen a los valores ni los sucesos a la intención; la vida interna real es inaccesible. Pero no del todo». Habla de acercarnos a través de la imaginación etnográficamente bien fundamentada, seleccionando fragmentos y resaltando momentos cruciales y encuentros dramáticos que dan forma y estilo a esas vidas y que apuntan de alguna manera al hecho creativo o fértil o sugerente (Lisón, 2005: 185). 
Quizás en este punto habría que tener presente lo que Roland Barthes indicó sobra la volatilidad del signo en la cultura japonesa: «El signo japonés es fuerte; admirablemente regulado, dispuesto, fijado, nunca se naturaliza o se racionaliza. El signo japonés está vacío: su significado huye, no hay dios, ni verdad, ni moral en el fondo en estos significantes que reinan sin contrapartida" (Barthes, 1991: 3). De manera que no al no haber sentido, esto afectaría al significado del cristianismo triunfante: "Todo en Zen sostiene una guerra contra la prevaricación del sentido" (Barthes, 1991: 98). Umberto Eco, con quien Lisón, si no recuerdo mal, viajó por China sostiene algo parecido (Eco, 1979). Japón es una caja llena de significados y significantes que interroga sobre todo a los semiólogos. Sabido es que la antropología desde The Chrysanthemum and the Sword de Ruth Benedict hasta Edward Hall y Claude Lévi-Strauss se han enfrentado a esta atracción por el rationale de los símbolos de la cultura nipona. Atracción que se ha visto corroborada en el presente con obras popularizadas en Europa como las de T. Tanisaki y el primer cine de Y. Ozu y A. Kurosawa.

Lisón, por lo además, consideraba al contrario que Y. Mishima, que veía periclitados los valores de los samuráis tras la Segunda Guerra Mundial - «ha dejado de haber samuráis, contiendas bélicas; la economía se ha recuperado; reina la paz; la juventud bosteza» (Mishima, 2016: 23)-, que éstos se incardinaban en la nueva cultura empresarial: "La férrea disciplina y agresividad profesional, la lealtad al clan y al daimio son transferidas ahora a la autoritaria y competitiva Corporación", aseverará Lisón (2013a: 370).

El libro del profesor Lisón Tolosana sobre Japón en el siglo XVI, puede que sea de los que menos impronta haya dejado en España, pero no deja de ser una investigación histórico-antropológica modélica de la alteridad más alejada, la japonesa. El profesor Lisón, que, según confesión propia, no quiso ir a hacer trabajo de campo, como le sugirió Evans-Pritchard, a Turquía, se enfrenta a un mundo lejano, más lejano aún. Y lo hace desde un habitus propio, el de aquellos sacerdotes de las penínsulas ibérica e italiana, que, siguiendo un racionalismo, contrapeso eficaz del fanatismo, encarnan cualidades heroicas. Ejercicio que realiza desde el conocimiento íntimo de quienes misionan. Más adelante continuará realizando nuevas reflexiones sobre el particular, señal inequívoca de que no lo abandonará la inquietud sembrada por la cuestión oriental nunca (Lisón, 2013b).

Nada de extrañar, si tenemos presente que Carmelo Lisón, hombre de Oxford, seguirá las pautas interpretativas de una cierta escuela británica, en la que casi todos sus maestros -Mary Douglas, Godfrey Lienhardt y Edward E. Evans-Pritchard- eran católicos, y se interrogaban por el símbolo en clave antropológica en consonancia son esa adscripción ideológica. Lienhardt había procurado comprender la religión como un todo en el cual la utilidad del ganado entre los dinkas tenía su proyección en el concepto de divinidad (Lienhardt, 1985). De hecho, se consideraba, según declararía años después Lienhardt, que la antropología oxoniense era un auténtico gueto militante, con ansias proselitistas, en un Oxford mayoritariamente anglicano. Adam Kuper les consagró estas líneas, tras constatar 
que Evans-Pritchard había abandonado el "método» propiamente funcional de Raclidffe-Brown, y que había optado por el «idealismo» e incluso el "historicismo»:

Los antropólogos de Oxford comenzaron a desarrollar una postura idealista que los situó al margen de sus colegas de todos los demás lugares de Inglaterra. Estas tendencias podrían haber estado relacionadas con el raro hecho de que varios de los miembros del departamento eran conversos a la Iglesia romana, incluyendo el propio Evans-Pritchard. En muchos casos los estudiantes que llegaban a Oxford se convertían primero a la postura teórica en boga y, posteriormente, al catolicismo; y el catedrático actuaba como padrino de sus bautizos (Kuper, 1973: 156).

La mayor parte de los conversos, y previamente no habían encajado en la London School of Economics, de Londres, donde se privilegiaba lo laicista. Participaban asimismo de cierta aversión al marxismo (Al-Shahi, 1999: 70).

Lo cierto es que, fuera anécdotas, la senda de una antropología de esta naturaleza ha sido muy incomprendida en España, donde el parteaguas de la religión y la irreligión, suele acabar por subsumir todo el debate posible, hasta convertirlo en un no debate. De ahí la opción final de Lisón cuando cruzara la antropología con la hermenéutica y en particular con las obras de los filósofos creyentes Gadamer (1988) y Ricoeur. Lisón Tolosana, oxoniense convicto, al margen de sus creencias, grandemente ocultas en el dominio de lo privado, respondía a la pulsión de conocimiento racional, en tanto universal antropológico. Acercándome a esta obra suya, comprendiéndola, incluso críticamente, he querido homenajear al maestro. El Extremo Oriente lo ponía frente a los problemas del símbolo radicalmente otro y frente al problema de la creencia, un tema antropológico el primero, verificado en su obra.

\section{REFERENCIAS BIBLIOGRÁFICAS ${ }^{2}$}

Al-shahi, A. (1999). Evans-Pritchard, Anthropology, and Catholicism at Oxford: Godfrey Lienhartd's view. Journal of Anthropological Society of Oxford, 30(1), pp. 67-72.

Barthes, R. (1991). El Imperio de los signos. Madrid: Mondadori.

Boxer, C. R. (1967). The Christian Century in Japan, 1549-1650. Berkeley: University of California Press.

Cieslik, H. S. J. (1974). The case of Cristovão Ferreira. Monumenta Nipponica, 29(1), pp. $1-54$.

Cortes, A. de las S. J. (1991). Viaje de la China. Madrid: Alianza. Edición crítica de Beatriz Moncó Rebollo. Prólogo Carmelo Lisón Tolosana.

2. N. B.: Finalizado este artículo tenemos constancia de la existencia del capítulo siguiente, que no hemos podido consultar a tiempo para incluir sus reflexiones: Asensi García De Cáceres, B. (2020). Algo que podemos aprender de la monografía "La fascinación de la diferencia» de Carmelo Lisón Tolosana. En H. Velasco Maíllo (ed.). Maestro Lisón: conversaciones, reflexiones y ensayos como celebración en sus 90 años y más (pp. 185-204). Zaragoza: Fundación Lisón \& Donald. 
Eco, U. (1979). Obra abierta. Barcelona: Ariel.

Endô, S. (1988). Silencio. Barcelona: Edhasa.

Fróis, L. (1585). Tratado sobre las Contradicciones y Diferencias en las Costumbres entre los Europeos y Japoneses. Edición de Osami Takizawa, con la colaboración de Tomoko Ietsuka. http://www.archivodelafrontera.com/wp-content/uploads/2020/02/FROISTAKIZAWA-Diferencia-de-costumbres-entre-japoneses-y-espa\%C3\%B1oles-15851.pdf.

Gadamer, H.-G. (1988). Verdad y método. Salamanca: Sígueme.

Gellner, D. N. (2001). The Anthropology of Buddism \& Hiunduism. Weberien Themes. Oxford: Oxford University Press.

González Alcantud, J. A. (2000). Interpretar y deconstruir el sentido y la acción política. En C. Lisón Tolosana (ed.), Antropología: horizontes interpretativos (pp. 43-58). Granada: Universidad de Granada \& Centro de Investigaciones Etnológicas «Ángel Ganivet».

González Alcantud, J. A. (2012). La estructura dramático local en el prisma antropológico de Lisón. Revista Anthropos, 235, pp. 140-150.

Gruzinski, S. (2013, 7. a). La colonización de lo imaginario. Sociedades indígenas y occidentalización en el México español. Siglos XVI-XVIII. México: FCE.

Gruzinski, S.; Mermet, G. (1994). L'Aigle et la Sybille. Fresques Indiennes du Mexique. París: Imprimerie Nationale.

Gunji, Y. (1985). Dall'isola del Giapan. La prima ambasceria giapponese in Occidente. Milán: Edizioni Unicopli.

Igawa, K. (2020). La «obediencia» de la primera embajada de Japón en Europa. O. Yoshimi y M. J. Zamora Calvo (eds.), Cruces y áncoras. La influencia de Japón y España en un Siglo de Oro global (pp. 12-38). Madrid: Abada

Kuper, A. (1973). Antropología y antropólogos. La escuela británica 1922-1972. Barcelona: Anagrama.

Lienhardt, G. (1985). Divinidad y experiencia. La religión de los dinkas. Madrid: Akal.

Lisón Tolosana, C. $\left(1978,2^{a}{ }^{a}\right)$. Un aragonés en China. En C. Lisón Tolosana, Ensayos de Antropología Social (pp. 11-39). Madrid: Ayuso.

Lisón Tolosana, C. (1983). Antropología social y hermenéutica. México: FCE.

Lisón Tolosana, C. (1992). El misionero (El difícil encuentro hispano-chino en los Siglos de Oro. En C. Lisón Tolosana. Individuo, estructura y creatividad. Etopeyas desde la Antropología Cultural (pp. 35-71). Madrid: Akal.

Lisón Tolosana, C. (2005). La fascinación de la diferencia. La adaptación de los jesuitas al Japón de los samuráis, 1549-1592. Madrid: Akal.

Lisón Tolosana, C. (2013a). La japonización de Japón (Cambio y permanencia, Antropología e Historia). En C. Lisón Tolosana, Antropología: estilos de pensamiento e interpretación (pp. 357-372). Barcelona: Anthropos.

Lisón Tolosana, C. (2013b). Occidente y Oriente en el escenario misionero japonés, 15491590. En: Anales de la Real Academia de Ciencias Morales y Políticas, 90, pp. 543-552.

Lugones, L. (1987). El imperio jesuítico. Buenos Aires: Hyspamérica.

Masamune, I. (1615). Historia del Regno di Voxu del Giapone, della Antichità, Nobiltà e Valore del suo Re. Roma: Giacomo Mascardi.

Mishima, Y. (2016, 2. ${ }^{\text {) }}$. La ética samurái en el Japón moderno. Madrid: Alianza.

Nagaoka, H. (1905). Histoire des rélations du Japon avec l'Europe aux XVIè et XVIIe siècles. París: H. Jouve.

Nenclares, E. M. de (1862). Vidas de los mártires del Japón. Madrid: Antonio Pérez Dubrull. Onfray, M. (2005). Traité d'athéologie. París: Grasset. 
Pinto Dos Santos, J. M. (2002). A 17th Century Buddhist Treatise Refuting Christianity. Bulletin of Portuguese-Japanese Studies, 4, pp. 91-110.

Ricard, R. (1986, orig. 1947). La conquista espiritual de México. Ensayo sobre el apostolado y los métodos misioneros de las órdenes mendicantes en la Nueva España de 1523-1524 a 1572. México: FCE.

Spadaro, A. S. J. (2017). Entretiens avec Martin Scorsese. Silence. París: Balland.

Whitney Hall, J. (1987, 8. ${ }^{a}$ ). El imperio japonés. México: Siglo XXI. 